\title{
THE IMPACT OF COVID-19 ON EXCHANGE RATE VOLATILITY: AN ECONOPHYSICS APPROACH
}

\author{
Rui Dias ${ }^{1}$ \\ Hortense Santos ${ }^{2}$
}

DOI: https://doi.org/10.31410/LIMEN.2020.39

\begin{abstract}
This paper aims to analyze the efficiency, in its weak form, between exchange rates, US-RMB, US-EUR, US-JPY, US-MYR, US-PHP, US-SGD, US-THB, US-CHF, US-GBP, in the period from July 1, 2019 to October 27, 2020. To perform this analysis, different approaches were undertaken to assess whether: (i) the impact of the global pandemic created long memories in international foreign exchange markets? The results of the exponents Detrended Fluctuation Analysis (DFA) show that the exchange rates US-THB (0.60), US-MYR (0.59), US$S G D$ (0. 59), present long memories, to a lesser extent the exchange pairs US-GBP (0.56), USEUR (0.53). On the other side, exchange rates US-RMB (0. 47), US-JPY (0. 43), US-CHF (0. 46), US-PHP (0. 38) show anti persistence, while the Detrended cross-correlation coefficient $(p D C C A)$ results show 19 average correlation coefficients $(\cong 0.333 \rightarrow \cong 0.666)$, 10 weak correlation coefficient $(\cong 0,000 \rightarrow \cong 0.333$ ), 7 strong non-trend cross correlation coefficients $(0.666 \rightarrow \cong 1,000)$. In conclusion, we show that the exchange pairs analyzed show some predictability, that is, there are levels of arbitrage that can be explored by investors; we also found that the exchange rates analyzed have characteristics of diversification, due to the low autocorrelation between markets. The objective of this study was not to analyze abnormal profitability by investors without incurring additional risk.
\end{abstract}

Keywords: Covid-19, Exchange rates, Efficiency, Arbitration, Portfolio diversification.

\section{INTRODUCTION}

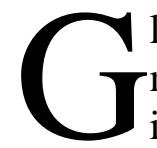
lobalization has accentuated the synchronization swells between international financial markets, demonstrating that the correlation between international financial markets has increased, particularly in times of extreme volatility. If a stock market in one country is integrated into another country's stock market, the financial stability of the former depends in part on the financial stability of the second. From the investor's point of view, knowledge of the form and intensity of interdependence between different financial markets is vital for efficient hedging decision-making, in order to minimize the adverse effect of uncertainty on expected return on investments. Likewise, the understanding of interdependence relations between international stock markets facilitates the identification of opportunities for diversification (Alexandre, Heliodoro and Dias, 2019; Dias, da Silva, and Dionysus, 2019; Dias, Heliodoro and Alexandre, 2019, 2020; Alexandre, Dias and Heliodoro, 2020; Heliodoro et al. , 2020, 2020; Heliodoro, Dias and Alexandre, 2020; Dias, Alexandre and Heliodoro, 2020, 2020; Dias, Heliodoro, et al. , 2020, 2020a, 2020b; Dias, Sparrow, et al. , 2020) .

\footnotetext{
1 School of Business and Administration, Polytechnic Institute of Setúbal, Portugal and CEFAGE-UE, IIFA, University of Évora, Portugal

2 School of Business and Administration, Polytechnic Institute of Setúbal, Portugal
} 
According to the authors Huang and Zhang (2019) the wealth that an entity has is usually composed of several assets or evaluated by different currencies, whose value depends on the fluctuation of exchange rates. The analysis of exchange rate dynamics concerns market agents, including individual investors, institutional investors, risk managers due to currency shocks, and their impact on the real value of assets.

Speculation in financial markets has been a process that aims to discover asset prices by investors in international financial markets. However, measures taken to mitigate this speculation have significantly reduced informational efficiency in foreign exchange markets. In view of these events this paper aims to test the efficiency, in its weak form, between the foreign exchange markets, US-RMB, US-EUR, US-JPY, US-MYR, US-PHP, US-SGD, US-THB, USCHF, US-GBP. To perform this analysis, different approaches were undertaken to assess whether: (i) the global pandemic promoted in (efficiency) in international foreign exchange markets? The results suggest that many foreign exchange markets are integrated (63 out of 90 possible), which could question portfolio diversification. The results of the exponents Detrended Fluctuation Analysis (DFA) show that the foreign exchange markets reject, in most cases, the random walk hypothesis. These findings have implications for investors, as some profitability can be expected, creating opportunities for arbitration and abnormal income.

This research adds relevant contributions to the literature. The most relevant contribution is related to the study of the reversal of the average in the international exchange markets, aiming to understand the different predictability between them, in the context of the global pandemic (Covid-19). As far as we know the authors Ning, Wang, and Su (2017), Matebejana, Motlaleng, and Juana (2017), Njindan Iyke (2019), Chaudhry, Hanif, Hassan, and Chani (2019), analyzed the reversal to the average in the foreign exchange markets, testing the random walk and, efficient market hypotheses, in its weak form, but the research questions, the markets analyzed, the sampling period, and the estimation models were different from the following in this trial.

In terms of structure this paper is organized in 5 sections. Section 2 presents a Literature Review regarding articles on the random walk hypothesis in international foreign exchange markets. Section 3 describes the methodology and data. Section 4 contains the results. Section 5 concludes.

\section{LITERATURE REVIEW}

Different studies have addressed the issue of market efficiency, analyzing the hypothesis of predictability of profitability, through the analysis of patterns of reversal to the average of stock prices, inspired by the seminal works of Poterba and Summers (1988), stock markets, on time horizons of more than one year.

Chiang, Lee, Su, and Tzou (2010), Sheik and Banu (2015), Palma and Sartoris (2016) tested the efficient market hypothesis (HME) in international foreign exchange markets. Chiang, Lee, $\mathrm{Su}$, and Tzou (2010) show that the foreign exchange markets of Japan, South Korea and the Philippines are efficient in their weak form, while in the Taiwan exchange market the random walk hypothesis is rejected. The authors Sheik and Banu (2015) tested market efficiency, in its weak form, in the exchange rates of China, Indonesia, and the U.S. in relation to the Indian rupee, showing that the exchange rates analyzed follow the random walk hypothesis, that is, investors will have many difficulties in obtaining anomic yields without incurring additional risk. The authors Palma and Sartoris (2016) examined the hypothesis of market efficiency, in 
its weak form, in the Brazilian foreign exchange market, showing that the exchange rates analyzed do not follow the random walk hypothesis, that is, investors will be able to obtain abnormal yields if they adjust their trading strategies.

Olufemi et al. (2017), Chaudhry et al. (2019) examined the random walk hypothesis in the exchange rates of several countries. Olufemi et al. (2017) examined the efficiency, in its weak form, in the foreign exchange markets of 10 countries in sub-Saharan Africa against the US dollar. The authors show the presence of long memories, and that the random walk hypothesis is rejected at all exchange rates, evidencing that time series are not independent and identically distributed (i.i.d.). Chaudhry et al. (2019) tested the random walk hypothesis in the exchange rates JPY/PKR, CHF/PKR, GBP/PKR, USD/PKR; the authors show the market efficiency, i.e., investors may have difficulty obtaining abnormal yields due to the arbitrage levels being very low.

In summary, this work aims to contribute to the provision of information to investors and regulators in the international exchange markets, where individual and institutional investors seek to efficiently diversify their portfolios, in a period of uncertainty and lack of confidence arising from the global pandemic (Covid-19).

\section{METHODOLOGY}

\section{Data}

The data used for the preparation of this research were exchange rates, US-RMB (US-China), US-EUR (US-ZONE Europe), US-JPY (US-Japan), US-MYR (US-Malaysia) US-PHP (USPhilippines), US-SGD (US-Singapore), US-THB (US-THAILAND), US-CHF (USSwitzerland), US-GBP (US-UK). The sample comprises the period from December 1, 2019 to October 27, 2020, and the data were extracted from the Thomson Reuters platform.

\section{Methodology}

The development of the research took place through several stages. In a first phase we chart the evolution of exchange rates in levels and returns. The characterization of the sample used was made through descriptive statistics, the adherence test of Jarque and Bera (1980), as well as quantiles graphs. To answer the first research question, we will use the Detrended Fluctuation Analysis (DFA) methodology. DFA is an analysis method that examines temporal dependence on non-stationary data series. This technique by assuming that time series are non-stationary avoids spurious results when the analysis focuses on the relationships of the data series in the long term. This methodology was developed by Peng et al. (1994), having the same its origin in the study of the behavior of $D N A$. Later this method was used to examine the behavior of financial series. DFA has the following interpretation: $0<\alpha<0,5$ : anti-persistent series; $\alpha=$ 0,5 series features random walk; $0,5<\alpha<1$ persistent series. The function of this technique is to examine the relationship between values $x_{k}$ and $x_{k+t}$ in differentiated moments (Sukpitak and Hengpunya, 2016; Guedes, Dionysus, Ferreira, and Zebende, 2017). Contemplate the dataset $x_{k}$ with $k=1, \ldots, t$ equidistant observations. DFA's first step is the construction of a new series:

$$
x(t)=\sum_{k=1}^{t} x_{k}
$$

The second step is to obtain the trend, $z(t)$ of each fraction through the least squares method, obtaining the subtracted series from the trend (detrended), i.e. 


$$
x_{s}(t)=x(t)-z(t)
$$

The original application assumes that the trend present in each of the boxes is a linear trend, $Z(t)=a t+b i$.e. subsequent applications indicate that it is likely to contain other polynomian tendencies, (Kantelhardt, Koscielny-Bunde, Rego, Havlin, and Bunde, 2001). For each box, the value of the trend equation is obtained by the least squares method and later the root of the mean square deviation between the series is estimated $x(t)$ and, $Z(t)$ being given the $D F A$ function by:

$$
F(s)=\sqrt{\frac{1}{2 N} \sum_{t=1}^{2 N}\left[x_{s}(t)\right]^{2}}
$$

Estimating the average $F(s)$ for all centralized boxes in $s$ generates the value of fluctuations $\langle F(s)\rangle$ depending on $s$. This estimation will be repeated to all the distinct values of s, waiting for a process of a power-law, that is:

$$
\langle F(s)\rangle \sim s \alpha^{\alpha}
$$

To answer the second research question, we will use the Detrended cross-correlation coefficient models, $p D C C A$. The cross-correlation coefficient depends on the length of the box $s$ (time scale). One of the advantages of this cross-correlation coefficient is centered on the possibility of measuring the correlations between two non-stationary time series at different time scales. The $D C C A$ cross-correlation coefficient varies within the logical range $-1 \leq \rho D C C A \leq 1$ where 1 means perfect cross correlation, -1 means perfect cross-correlation and 0 means that there is no correlation (Podobnik and Stanley, 2008). Table 1 shows the interpretation of the exponent. $p D C C A$

Table 1. Detrended cross-correlation coefficient, $p D C C A$.

\begin{tabular}{|c|c|c|}
\hline Weak & Medium & Strong \\
\hline$\cong 0,000 \rightarrow \cong 0.333$ & $\cong 0.333 \rightarrow \cong 0.666$ & $\cong 0.666 \rightarrow \cong 1,000$ \\
\hline
\end{tabular}

Source: Own elaboration

\section{RESULTS}

Figure 1 shows the fluctuations, in levels, of the exchange markets, US-RMB (US-China), USEUR (US-ZONE Europe), US-JPY (US-Japan), US-MYR(US-Malaysia), US-PHP (USPhilippines), US-SGD (US-Singapore), US-THB (US-THAILAND), US-CHF (USSwitzerland), US-GBP-GBP-(US-UK). The sample comprises the time horizon from July 1, 2019 to October 27, 2020, and it is a period of great complexity, due to understanding the global pandemic (Covid-19). The exchange rates analyzed clearly show the instability experienced in these markets in the first quarter of 2020. 
Figure 1. Evolution, in levels, of exchange rates, in the period from July 1, 2019 to October
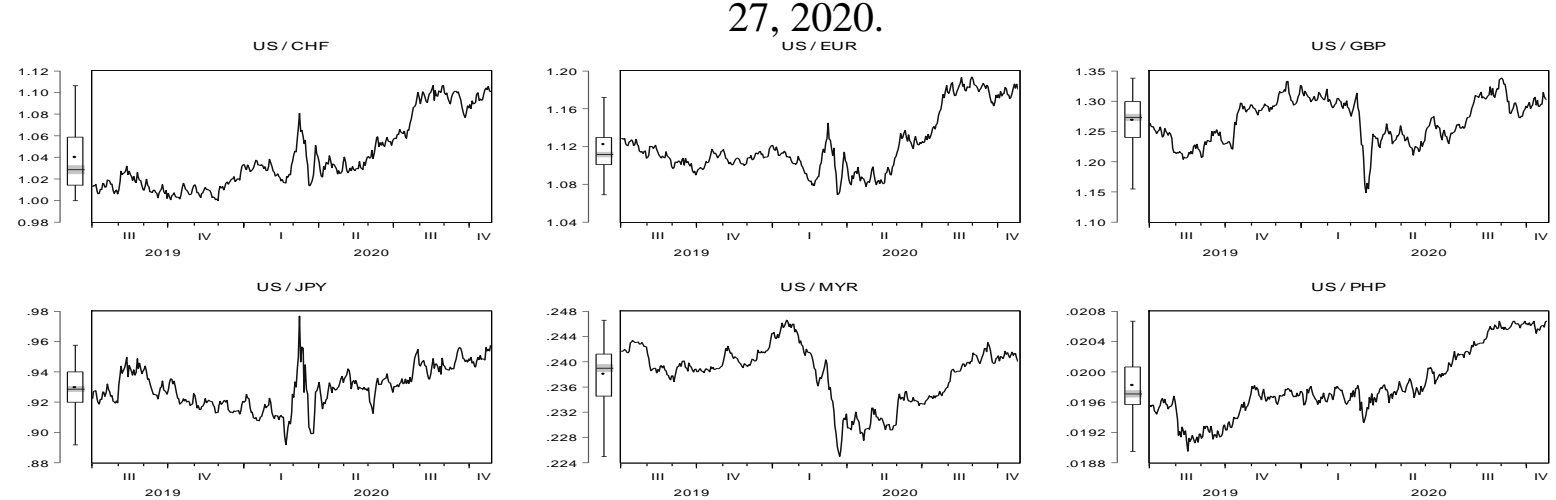

US/PHP

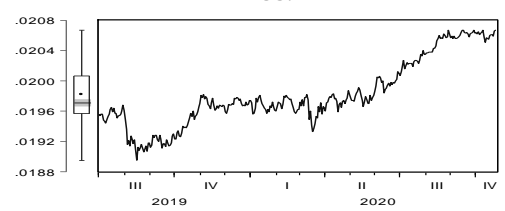

US/SGD
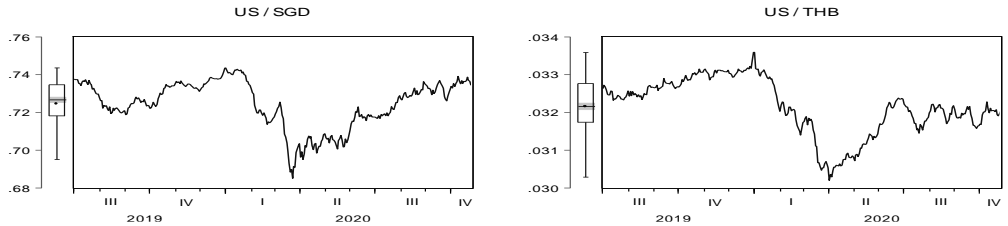

Note: Thomson Reuters, July 1, 2019, 348-point data.

Source: Own elaboration

Figure 2 shows the evolutions, return, of the exchange markets under analysis, and we can see that exchange rates have a relatively high dispersion around the average, as well as a relatively synchronized behavior between the data series. Through graphical analysis, high volatility is observed in the first quarter of 2020.

Figure 2. Evolution, return, exchange rates, from July 1, 2019 to October 27, 2020.
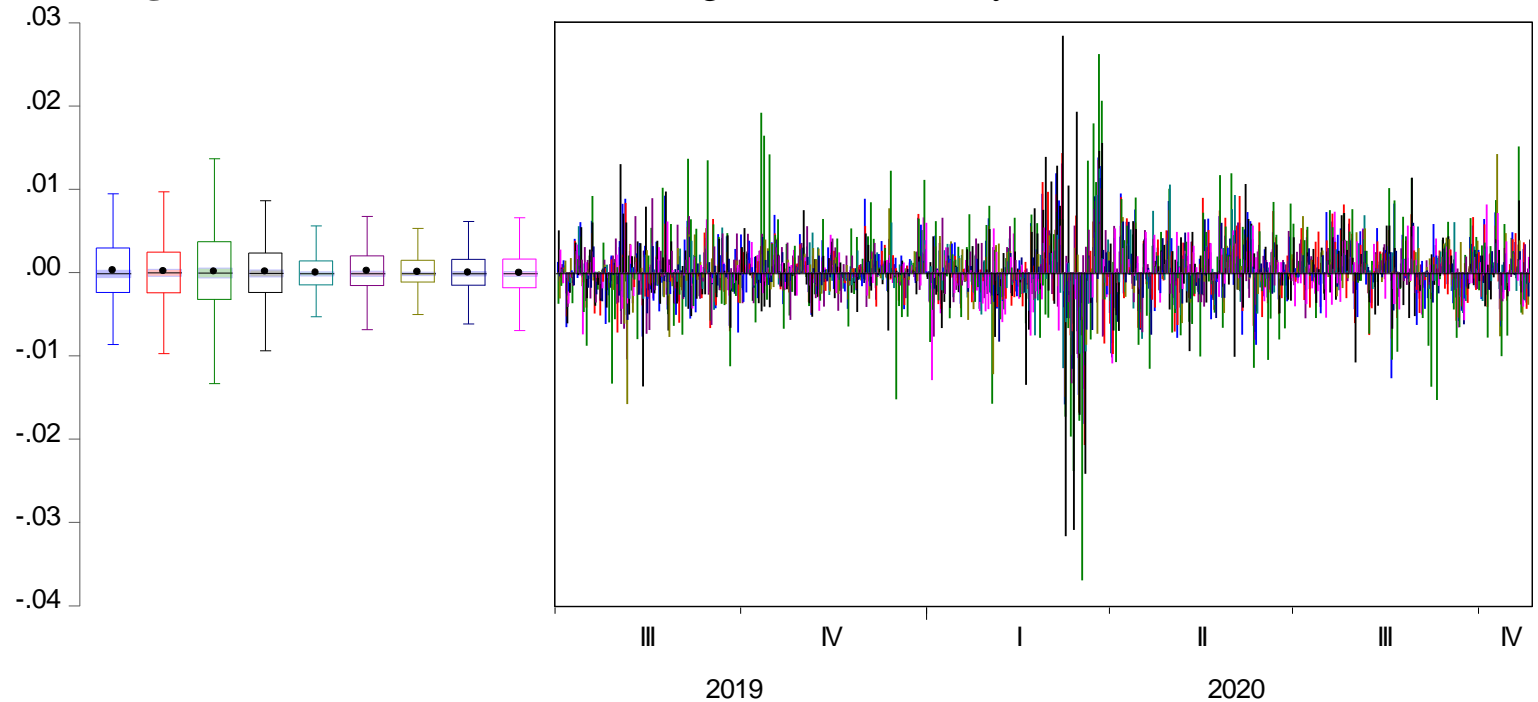

Note: Thomson Reuters: July 1, 2019, 347-point data.

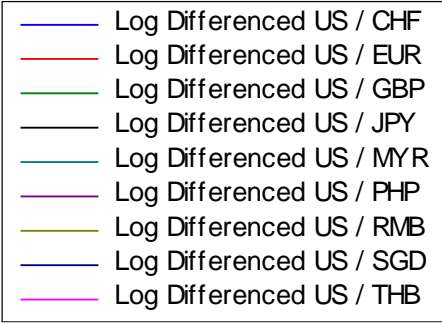

Source: Own elaboration 
Figure 3 shows the average exchange rate yields, and we can verify that exchange pairs USRMB (6.21E-05), US-EUR (0.000127), US-JPY (0.000109), US-PHP (0.000159), US-CHF (0.0.000240), US-GBP (9.08E-05), have positive average yields, while exchange rates USMYR (-1.81E-05), US-SGD (-1.06E-05), US-THB (-5.26E-05) show negative averages.

Figure 3. Evolution of average exchange rate yields from July 1, 2019 to October 27, 2020.
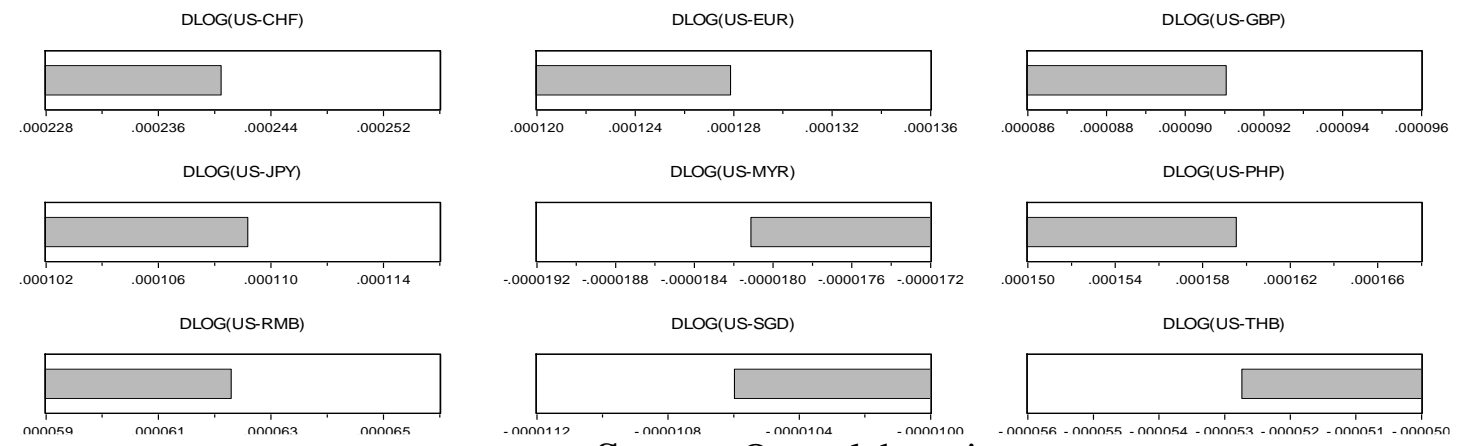

Source: Own elaboration

Figure 4 shows the standard deviations of the 9 exchange rates in analysis. As with averages, standard deviations also have very similar values, the exchange pairs that present the sharpest standard deviations are the US-GBP (0.006499), US-JPY (0.005227) rates. Exchange pairs USCHF (0.004223), US-EUR (0.004204), US-PHP (0.003010), US-THB (0.002 999), US-MYR (0.002903), US-RMB (0.002750) US-SGD (0.002698) have less pronounced standard deviations.

Figure 4. Evolution of standard deviations in exchange rates from July 1, 2019 to October 27, 2020.

Standard Deviations

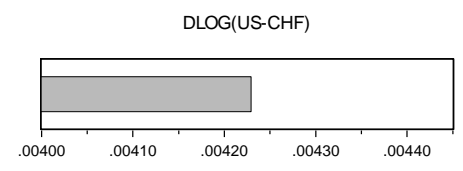

DLOG(US-EUR)
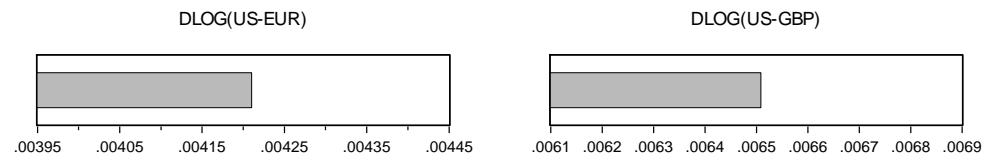

DLOG(US-JPY)

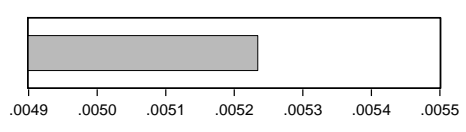

DLOG(US-MYR)

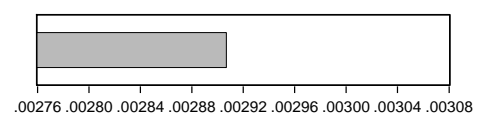

DLOG(US-PHP)

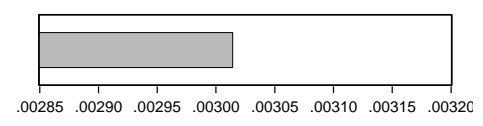

DLOG(US-SGD)

DLOG(US-THB)
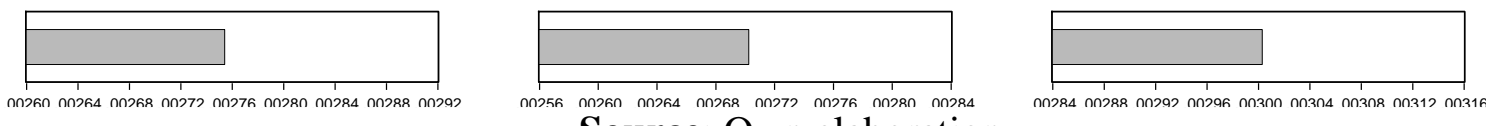

Source: Own elaboration

Figure 5 shows the Skewness of the 9 exchange pairs, and we can verify that most, exchange rates show negative asymmetries, US-JPY (-0.788139), US-RMB (-0.64 4040), US-THB (0.627525), US-PHP (-0.472917), US-GBP (-0.441958), US-SGD (-0.392 762), US-EUR (0.282775), US-CHF (-0.154701), except for exchange pair US-MYR (0.088298). These results indicate that the data do not follow a normal distribution (Skewness $=0$ ). 
Figure 5. Evolution of skewness of exchange rates from July 1, 2019 to October 27, 2020.
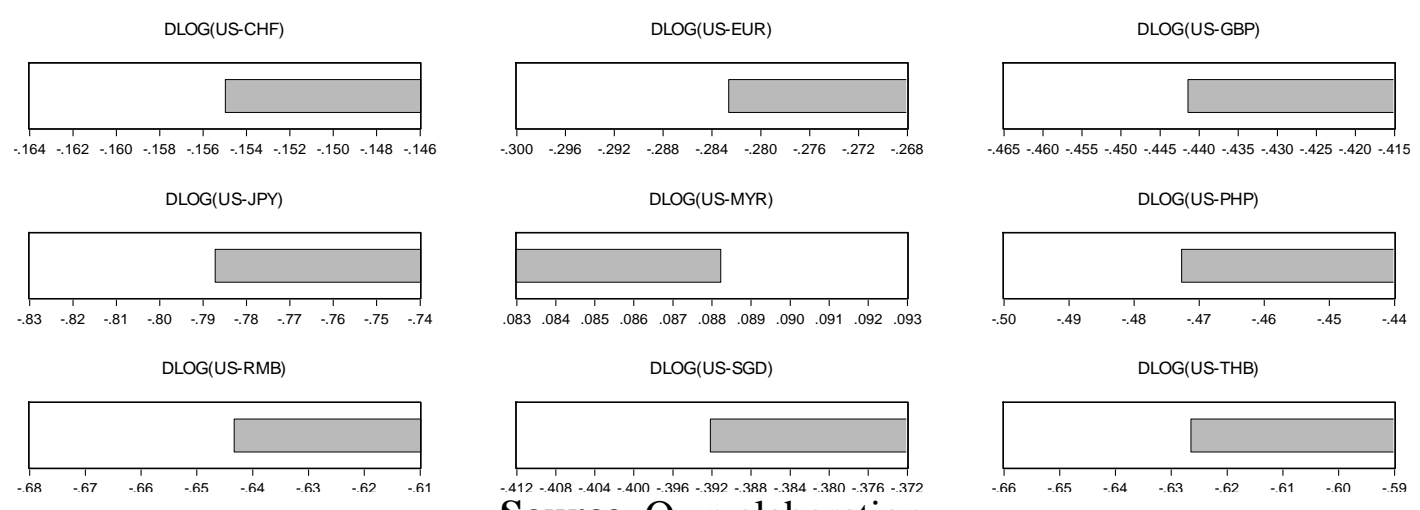

Source: Own elaboration

Figure 6 shows the Kurtosis of the US-RMB (US-China), US-EUR (US-EURO-Europe), USJPY (US-Japan) exchange markets, US-MYR (US-MALAYSIA), US-PHP (US-Philippines), US-SGD (US-Singapore), US-THB (US-THAILAND), US-CHF (US-Switzerland), US-GBP (US-GBP). Based on the results the time series do not follow normal distributions, represented by US-JPY (13.94465), US-RMB (9.134370), US-GBP (7.168678), US-MYR (5.839833), USSGD (5.SGD 663754), US-EUR (5.469931), US-THB (5.362836), US-CHF (4.809015), USPHP (4.412797). These results confirm the assumptions that time series do not follow a normal distribution, because asymmetry is different from reference values (Skewness $=0$; Kurtosis $=$ $3)$.

Figure 6. Evolution of exchange rate kurtosis from July 1, 2019 to October 27, 2020.

DLOG(US-CHF)

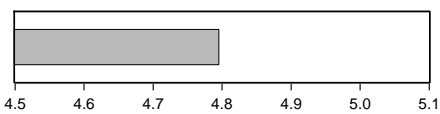

DLOG(US-JPY)

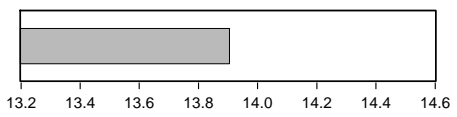

DLOG(US-RMB)

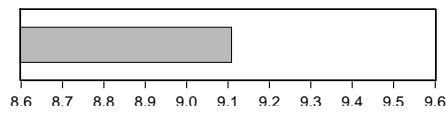

DLOG(US-EUR)

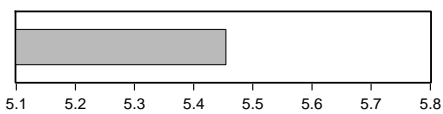

DLOG(US-MYR)

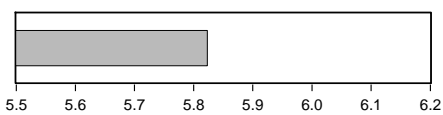

DLOG(US-SGD)

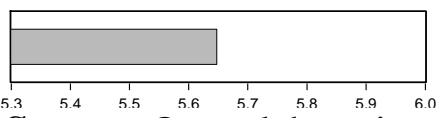

Source: Own elaboration
DLOG(US-GBP)

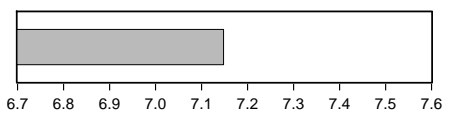

DLOG(US-PHP)

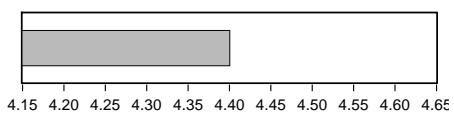

DLOG(US-THB)

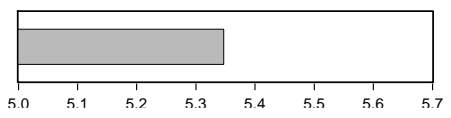

The graphs of quants show that the distribution of profitability rates are leptokurtic and asymmetric or biased. The distribution is leptokurtic because the graph is shaped like "S", on the $45^{\circ}$ line, and is asymmetric because the " $\mathrm{S}$ " is not symmetrical on the line, evidencing the existence of nonlinear relationships (see figure 7).

Table 2 shows the results of the exponents Detrended Fluctuation Analysis (DFA), and we found that the exchange rates US-THB (0.60), US-MYR (0.59), US-SGD (0.59), present long memories, and to a lesser extent the exchange pairs US-GBP (0.56), US-EUR (0.53). On the other side, exchange rates US-RMB (0. 47), US-JPY (0. 43), US-CHF (0. 46), US-PHP (0. 38) show anti persistence. These findings show that foreign exchange markets have some predictability, i.e., investors may have abnormal gains without incurring additional risk. These results are partially corroborated by the authors (Palma \& Sartoris, 2016), Olufemi et al. (2017) 
who tested the hypothesis of market efficiency (HME) in several foreign exchange markets, evidencing that the hypothesis of random walk and informational efficiency is rejected.

Figure 7. Graphs of the 9 exchange rates from July 1, 2019 to October 27, 2020.

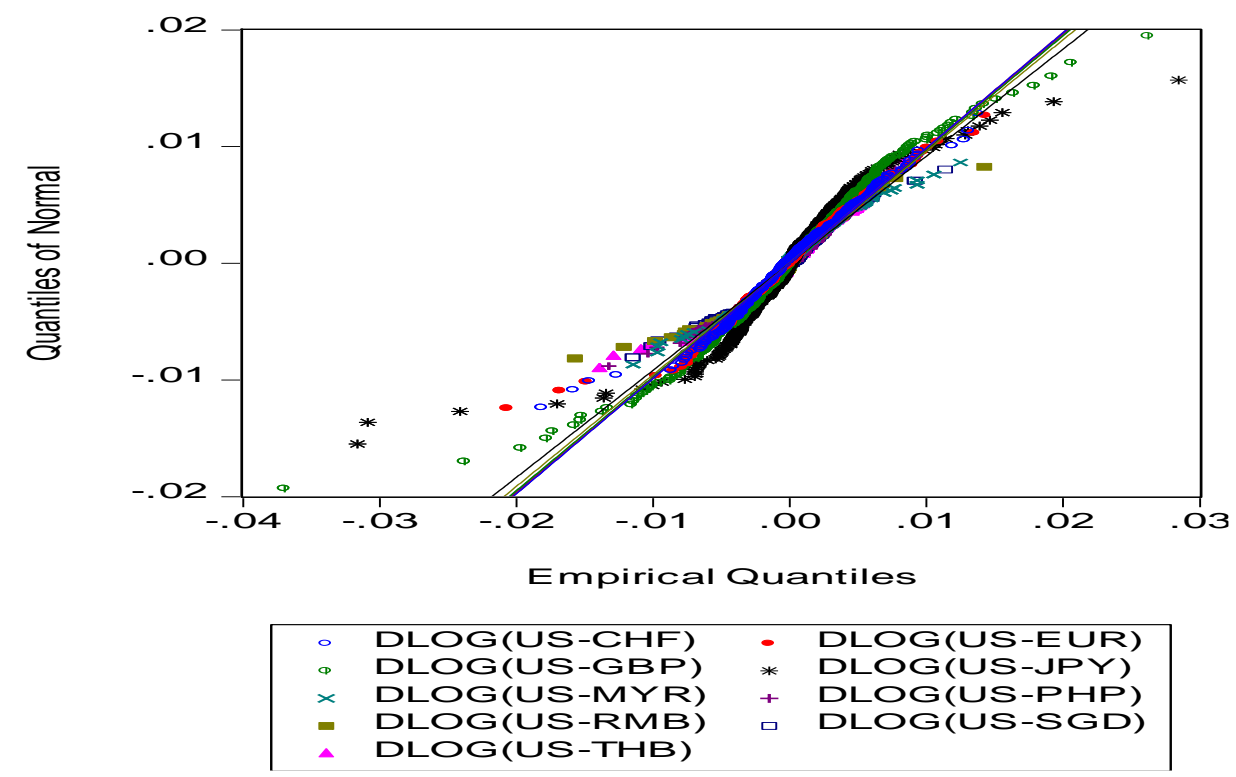

Source: Own elaboration

Table 2. DFA exponent for return. The values of the linear adjustments always had > $0.99 \alpha D F A R^{2}$

\begin{tabular}{|c|c|}
\hline Index & Exponent DFA (Covid-19) \\
\hline US/RMB & $0.47 \cong 0.0135$ \\
\hline US/EUR & $0.53 \cong 0.0236$ \\
\hline US/JPY & $0.43 \cong 0.0768$ \\
\hline US/MYR & $0.59 \cong 0.0169$ \\
\hline US/PHP & $0.38 \cong 0.0242$ \\
\hline US/SGD & $0.59 \cong 0.0159$ \\
\hline US/CHF & $0.46 \cong 0.0389$ \\
\hline US/THB & $0.60 \cong 0.0035$ \\
\hline US/GBP & $0.56 \cong 0.0452$ \\
\hline
\end{tabular}

Note: The hypotheses are: $H_{0} \alpha=0.5$ and: $H_{1} \alpha \neq 0.5$

Source: Own elaboration

Table 3 shows the results of Detrended cross-correlation coefficient (pDCCA)for exchange rates US-RMB (US-China), US-EUR (US-Zone Europe), US-JPY (US-Japan), US-MYR (USMalaysia), US-PHP (US-Philippines), US-SGD (US-Singapore), US-THB (US-Thailand), USCHF (US-Switzerland), US-GBP (US-UK). The rhoDCCA show 19 average correlation coefficients $(\cong 0.333 \rightarrow \cong 0.666), 10$ weak correlation coefficients $(\cong 0,000 \rightarrow \cong 0.333), 7$ strong trendless cross-correlation coefficients $(0.666 \rightarrow \cong 1,000)$. These findings show that the exchange rates analyzed have characteristics of diversification, due to the low autocorrelation between markets. 
Table 3. Table summary of rhoDCCA coefficients for the 9 exchange rates from July 1 , 2019 to October 27, 2020.

\begin{tabular}{|c|c|c|c|}
\hline Index & rhoDCCA & Time scale (days) & Trend \\
\hline US-RMB / US-EUR & 0.28 & $\mathrm{n}>19$ days & Weak \\
\hline US-RMB / US-JPY & 0.12 & $\mathrm{n}>37$ days & Weak \\
\hline US-RMB /US-MYR & 0.60 & $\mathrm{n}>18$ days & Medium \\
\hline US-RMB / US-PHP & 0.35 & $\mathrm{n}>12$ days & Medium \\
\hline US-RMB / US-SGD & 0.52 & $\mathrm{n}>13$ days & Medium \\
\hline US-RMB /US-CHF & 0.17 & $\mathrm{n}>17$ days & Weak \\
\hline US-RMB /US-THB & 0.27 & $\mathrm{n}>10$ days & Weak \\
\hline US-RMB / US-GBP & 0.34 & $\mathrm{n}>17$ days & Medium \\
\hline US-EUR / US-JPY & 0.56 & $\mathrm{n}>13$ days & Medium \\
\hline US-EUR / US-MYR & 0.54 & $n>14$ days & Medium \\
\hline US-EUR / US-PHP & 0.14 & $\mathrm{n}>10$ days & Weak \\
\hline US-EUR / US-SGD & 0.71 & n > 12 days & Strong \\
\hline US-EUR / US-CHF & 0.82 & $n>8$ days & Strong \\
\hline US-EUR / US-THB & 0.42 & $\mathrm{n}>14$ days & Medium \\
\hline US-EUR / US-GBP & 0.71 & n > 12 days & Strong \\
\hline US-JPY / US-MYR & 0.21 & $\mathrm{n}>12$ days & Weak \\
\hline US-JPY / US-PHP & 0.16 & $\mathrm{n}>10$ days & Weak \\
\hline US-JPY / US-SGD & 0.41 & $\mathrm{n}>13$ days & Medium \\
\hline US-JPY / US-CHF & 0.70 & n > 16 days & Strong \\
\hline US-JPY/ US-THB & 0.20 & $n>12$ days & Weak \\
\hline US-JPY / US-GBP & 0.41 & $\mathrm{n}>8$ days & Medium \\
\hline US-MYR / US-PHP & 0.39 & $\mathrm{n}>15$ days & Medium \\
\hline US-MYR / US-SGD & 0.76 & n > 16 days & Strong \\
\hline US-MYR /US-CHF & 0.41 & $\mathrm{n}>11$ days & Medium \\
\hline US-MYR /US-THB & 0.39 & $\mathrm{n}>13$ days & Medium \\
\hline US-MYR / US-GBP & 0.52 & $\mathrm{n}>12$ days & Medium \\
\hline US-PHP / US-SGD & 0.42 & $\mathrm{n}>9$ days & Medium \\
\hline US-PHP / US-CHF & 0.06 & $n>14$ days & Weak \\
\hline US-PHP/ US-THB & 0.29 & $\mathrm{n}>13$ days & Weak \\
\hline US-PHP / US-GBP & 0.34 & $\mathrm{n}>26$ days & Medium \\
\hline US-SGD / US-CHF & 0.67 & n > 24 days & Strong \\
\hline US-SGD/ US-THB & 0.55 & $\mathrm{n}>20$ days & Medium \\
\hline US-SGD / US-GBP & 0.70 & n > 10 days & Strong \\
\hline US-CHF/ US-THB & 0.48 & $\mathrm{n}>11$ days & Medium \\
\hline US-CHF / US-GBP & 0.59 & $\mathrm{n}>8$ days & Medium \\
\hline US-THB / US-GBP & 0.36 & $\mathrm{n}>15$ days & Medium \\
\hline
\end{tabular}

Source: Own elaboration

\section{CONCLUSION}

The general conclusion to be withheld and sustained in the results obtained, through tests carried out with econophysical models show that the global pandemic of 2020 affected the memory 
properties of these exchange markets. The results indicate that markets have persistence and long memories, implying that investors will be able to achieve anomic yields without incurring additional risk. Most rhoDCCA of them show medium and low correlation coefficients, which shows that the implementation of portfolio diversification strategies may be feasible. We can conclude that although the random walk hypothesis has been rejected in all markets, the essential condition of diversification and coverage in these foreign exchange markets can be exploited by international investors in order to maximize the profitability of their portfolios, as well as mitigate the risk arising from the uncertainty and pessimism that was present in 2020 in the international financial markets.

\section{REFERENCES}

Alexandre, P., Dias, R., \& Heliodoro, P. (2020). EUROPEAN FINANCIAL MARKET INTEGRATION: A CLOSER LOOK AT GOVERNMENT BONDS IN EUROZONE COUNTRIES. Balkans Journal of Emerging Trends in Social Sciences. https://doi.org/10.31410/balkans.jetss.2020.3.1.78-86.

Alexandre, P., Heliodoro, P., \& Dias, R. (2019). THE CONTAGION EFFECT IN EUROPE: A DCC GARH APPROACH. In 5th LIMEN Conference Proceedings (part of LIMEN conference collection). https://doi.org/10.31410/limen.2019.73

Chaudhry, A. F., Hanif, M.M., Hassan, S., \& Chani, M. I. (2019). Efficiency of the Black Foreign Exchange Market. International Journal of Economics and Finance. https://doi.org/10.5539/ijef.v11n2p165

Chiang, S.M., Lee, Y. H., Su, H.M., \& Tzou, Y. P. (2010). Efficiency tests of foreign exchange markets for four Asian Countries. Research in International Business and Finance. HTTPS://DOI.ORG/10.1016/J.RIBAF.2010.01.001

Dias, R., Alexandre, P., \& Heliodoro, P. (2020). Contagion in the LAC Financial Markets: The Impact of Stock Crises of 2008 and 2010. Littera Scripta. https://doi.org/10.36708/littera_scripta2020/1/3

Dias, R., da Silva, J. V., \& Dionysus, A. (2019). Financial markets of the LAC region: Does the crisis influence the financial integration? International Review of Financial Analysis, 63(January), 160-173. https://doi.org/10.1016/j.irfa.2019.02.008

Dias, R., Heliodoro, P., \& Alexandre, P. (2019). RISK TRANSMISSION AMONG STOCK MARKETS IN LAC REGION: FINANCIAL CRISES IMPACT. In 5th LIMEN Selected Papers (part of LIMEN conference collection). https://doi.org/10.31410/limen.s.p.2019.91

Dias, R., Heliodoro, P., \& Alexandre, P. (2020). Efficiency of Asean-5 Markets: An Detrended Fluctuation Analysis. Mednarodno Inovativno Poslovanje $=$ Journal of Innovative Business and Management. https://doi.org/10.32015/jibm.2020.12.2.13-19

Dias, R., Heliodoro, P., Alexandre, P., \& Vasco, C. (2020a). FINANCIAL MARKET INTEGRATION OF ASEAN-5 WITH CHINA: AN ECONOPHYSICS APPROACH. In 4th EMAN Conference Proceedings (part of EMAN conference collection) https://doi.org/10.31410/eman.2020.17

Dias, R., Heliodoro, P., Alexandre, P., \& Vasco, C. (2020b). THE SHOCKS BETWEEN OIL MARKET TO THE BRIC STOCK MARKETS: A GENERALIZED VAR APPROACH. In 4th EMAN Conference Proceedings (part of EMAN conference collection). https://doi.org/10.31410/eman.2020.25

Dias, R., Pardal, P., Teixeira, N., \& Machová, V. (2020). Financial Market Integration of ASEAN-5 with China. Littera Scripta. https://doi.org/10.36708/littera_scripta2020/1/4

Fame, E. F., \& French, K. R. (1988). Dividend yields and expected stock returns. Journal of Financial Economics. https://doi.org/10.1016/0304-405X(88)90020-7

Heliodoro, P., Dias, R., \& Alexandre, P. (2020). FINANCIAL CONTAGION BETWEEN THE 
US AND EMERGING MARKETS: COVID-19 PANDEMIC CASE. In 4th EMAN
Selected Papers (part of EMAN conference collection). https://doi.org/10.31410/eman.s.p.2020.1

Heliodoro, P., Dias, R., Alexandre, P., \& Vasco, C. (2020). INTEGRATION IN BRIC STOCK MARKETS: AN EMPIRICAL ANALYSIS. In 4th EMAN Selected Papers (part of EMAN conference collection). https://doi.org/10.31410/eman.s.p.2020.33

Huang, H., \& Zhang, Z. (2019). Virtual Standard Currency for Approximating Foreign Exchange Rates. International Journal of Electronic Commerce. https://doi.org/10.1080/10864415.2018.1512273

Jarque, C.M., \& Bera, A. K. (1980). Efficient tests for normality, homoscedasticity and serial independence of regression residuals. Economics Letters, 6(3), 255-259. https://doi.org/10.1016/0165-1765(80)90024-5

Kantelhardt, J. W., Koscielny-Bunde, E., Rego, H. H., Havlin, S., \& Bunde, A. (2001). Detecting long-range correlations with detrended fluctuation analysis. Physica A: Statistical Mechanics and Its Applications, 295(3-4), 441-454. https://doi.org/10.1016/S0378-4371(01)00144-3

Matebejana, G., Motlaleng, G., \& Juana, J. (2017). Foreign Exchange Market Efficiency In Botswana. Review of Economic and Business Studies. https://doi.org/10.1515/rebs-20170050

Ning, Y., Wang, Y., \& Su, C. Wei. (2017). How did China's foreign exchange reform affect the efficiency of foreign exchange market? Physica A: Statistical Mechanics and Its Applications. https://doi.org/10.1016/j.physa.2017.04.150

Njindan Iyke, B. (2019). A TEST OF THE EFFICIENCY OF THE FOREIGN EXCHANGE MARKET IN INDONESIA. Buletin Ekonomi Moneter Dan Perbankan. https://doi.org/10.21098/bemp.v0i0.976

Olufemi, A. P., Adewale, A. O., \& Oseko, M. S. (2017). Efficiency of Foreign Exchange Markets in Sub-Saharan Africa in the Presence of Structural Break: A Linear and NonLinear Testing Approach. Journal of Economics and Behavioral Studies. https://doi.org/10.22610/jebs.v9i4.1827.

Palma, A. A., \& Sartoris, A. (2016). Weak-Form Market Efficiency of the Brazilian Exchange Rate: Evidence from an Artificial Neural Network Model. Latin American Business Review. https://doi.org/10.1080/10978526.2016.1171720

Peng, C. K., Buldyrev, S. V., Havlin, S., Simons, M., Stanley, H. E., \& Goldberger, A. L. (1994). Mosaic organization of DNA nucleotides. Physical Review E, 49(2), 1685-1689. https://doi.org/10.1103/PhysRevE.49.1685

Podobnik, B., \& Stanley, H. E. (2008). Detrended cross-correlation analysis: A new method for analyzing two nonstationary time series. Physical Review Letters, 100(8). https://doi.org/10.1103/PhysRevLett.100.084102

Poterba, J.M., \& Summers, L. H. (1988). Mean reversion in stock prices. Evidence and Implications. Journal of Financial Economics. https://doi.org/10.1016/0304405X(88)90021-9

Sheik, M.M., \& Banu, M. A. S. (2015). Study on Weak-Form Efficiency of Foreign Exchange Markets of Developing Economies: Some India Evidence. International Journal of Management.

Sukpitak, J., \& Hengpunya, V. (2016). Efficiency of Thai stock markets: Detrended fluctuation analysis. Physica A: Statistical Mechanics and Its Applications, 458, 204-209. https://doi.org/10.1016/j.physa.2016.03.076 